\title{
Arsenicosis Presenting with Cutaneous Squamous Cell Carcinoma: A Case Report
}

\author{
Marie Len A. Camaclang, ${ }^{1}$ Eileen Liesl A. Cubillan ${ }^{2}$ and Claudine Yap-Silva² \\ ${ }^{1}$ Section of Dermatology, Department of Medicine, Philippine General Hospital, University of the Philippines Manila \\ ${ }^{2}$ Section of Dermatology, Department of Medicine, College of Medicine and Philippine General Hospital, University of the Philippines Manila
}

\begin{abstract}
A 29-year-old male with eleven-year history of hyperkeratotic papules and speckled pigmentation developed cutaneous squamous cell carcinoma. Arsenicosis was confirmed by elevated hair arsenic level, and histopathologic findings of arsenical keratosis and one lesion showing carcinoma-in-situ. Chronic arsenic exposure has been found to activate inflammatory and carcinogenic pathways leading to development of pre-malignant and malignant lesions. A multi-disciplinary approach involving healthcare specialists and environmentalists is crucial in source control and management of long-term complications.
\end{abstract}

Key Words: arsenic, arsenic poisoning, arsenicosis, skin cancer, squamous cell carcinoma

\section{INTRODUCTION}

Paper presented at the Philippine General Hospital (PGH) Department of Medicine Research Forum, November 21-28, 2017, PGH, Manila; $1^{\text {st }}$ place, Case Report Category, Manila, Philippines.

E-poster presented at the $40^{\text {th }}$ Annual Convention of the Philippine Dermatological Society, November 8-10, 2017, EDSA Shangri-La, Mandaluyong City, Philippines.

E-poster presented at the 2019 American Academy of Dermatology Annual Meeting, March 1-5, 2019, Washington DC, USA.

Corresponding author: Marie Len A. Camaclang, MD Section of Dermatology

Department of Medicine

Philippine General Hospital

University of the Philippines Manila

Padre Faura, Ermita, Manila 1000, Philippines

Telephone: +632 5548400 local 5105/5106

Email: macamaclang@up.edu.ph
Arsenic is a potential human carcinogen of public health concern. Exposure may be via inhalation of arsenic dusts, direct contact with arsenites, or ingestion of contaminated water, the latter being the most common route. ${ }^{1}$ Chemical contamination of groundwater may come from natural sources such as geochemical processes (e.g. volcanic activities), as well as the result of human activities including mining wastes, landfills, and industrial spillage. ${ }^{1}$ The World Health Organization (WHO) has set a provisional guideline arsenic value of less than $10 \mathrm{ug} / \mathrm{L}$ for drinking water. ${ }^{1}$

Individuals with chronic exposure to this ubiquitous metalloid, termed arsenicosis, may remain asymptomatic for a long time. Characteristic cutaneous manifestations such as arsenic keratoses and pigmentary changes are the earliest dermatological manifestations, and the primary reason for individuals to seek consult; ${ }^{2}$ hence, the skin plays a major role in recognition and diagnosis.

Affected individuals are at increased risk of longterm complications, which include cutaneous and internal malignancies. We report the first documented case of arsenicosis from Laguna who presented with cutaneous carcinoma. The patient became the index patient for subsequent community health assessment.

\section{CASE REPORT}

A 29-year-old male from Los Baños, Laguna presented with an 11-year history of multiple hyperkeratotic papules and generalized speckled pigmentation (Figure 1). A biopsy-proven squamous cell carcinoma (Figure 2A) was noted to develop from a fungating tumor on the left hand. 
This tumor, rapidly enlarging in a span of eleven months, was noted to develop from traumatic manipulation of one of the hyperkeratotic papules. Review of systems and past medical history were unremarkable. He was a previous one pack-year smoker, an occasional alcoholic beverage drinker, who denied any history of illicit drug use.

The presence of similar lesions in household members, and allegedly in selected neighbors, warranted further investigation on the patient's personal and social history. On further probing, the patient has been residing near a local dormant volcano (Mount Makiling) for twenty years, with drinking water coming from groundwater supply.

On physical examination, there were multiple brown to flesh-colored hyperkeratotic papules and plaques distributed on the trunk, upper and lower extremities, and acral areas, over a background of speckled pigmentation (Figure 1). On the left ventral hand, there was a solitary, irregularlyshaped well-defined, fungating, foul-smelling tumor with an erythematous border and granular purulent base (Figure 2A). There was neither lymphadenopathy nor organomegaly on palpation. Biopsy of hyperkeratotic lesions from the left ventral hand and from the left thigh showed features consistent with arsenical keratosis (Figure 2B) and with squamous cell carcinoma in-situ (Figure $2 \mathrm{C}$ ), respectively.

Clinical and histological findings were consistent with arsenicosis. This was further supported by hair sample sent by the Department of Toxicology, which showed elevated arsenic level $(19 \mathrm{mg} / \mathrm{kg}$, normal value: $<1 \mathrm{mg} / \mathrm{kg})$. His mother
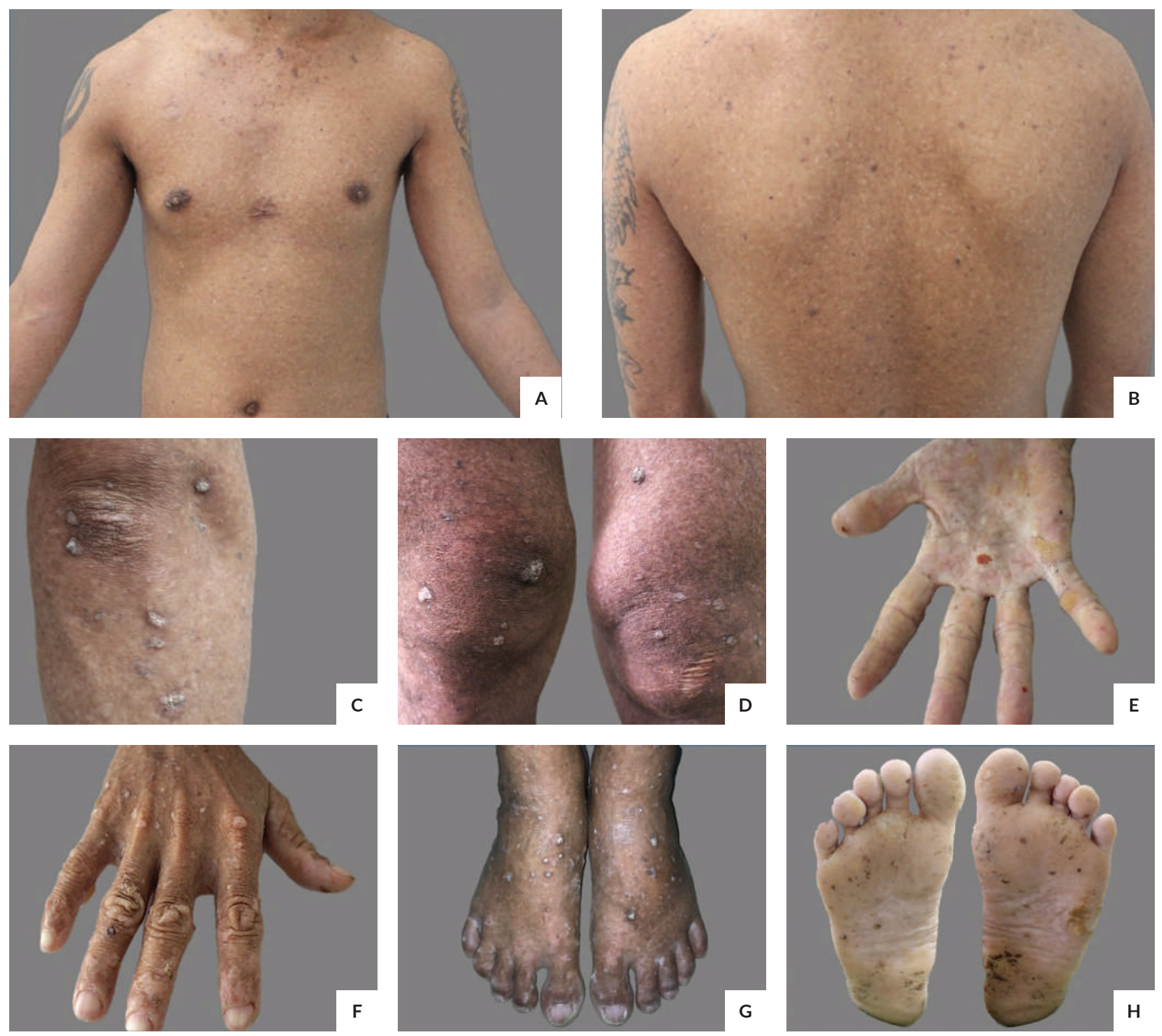

Figure 1. Cutaneous Findings. Multiple brown to flesh-colored hyperkeratotic papules and plaques over a background of speckled pigmentation distributed on the trunk (A-B), upper and lower extremities (C-D), and acral areas (E-H). 

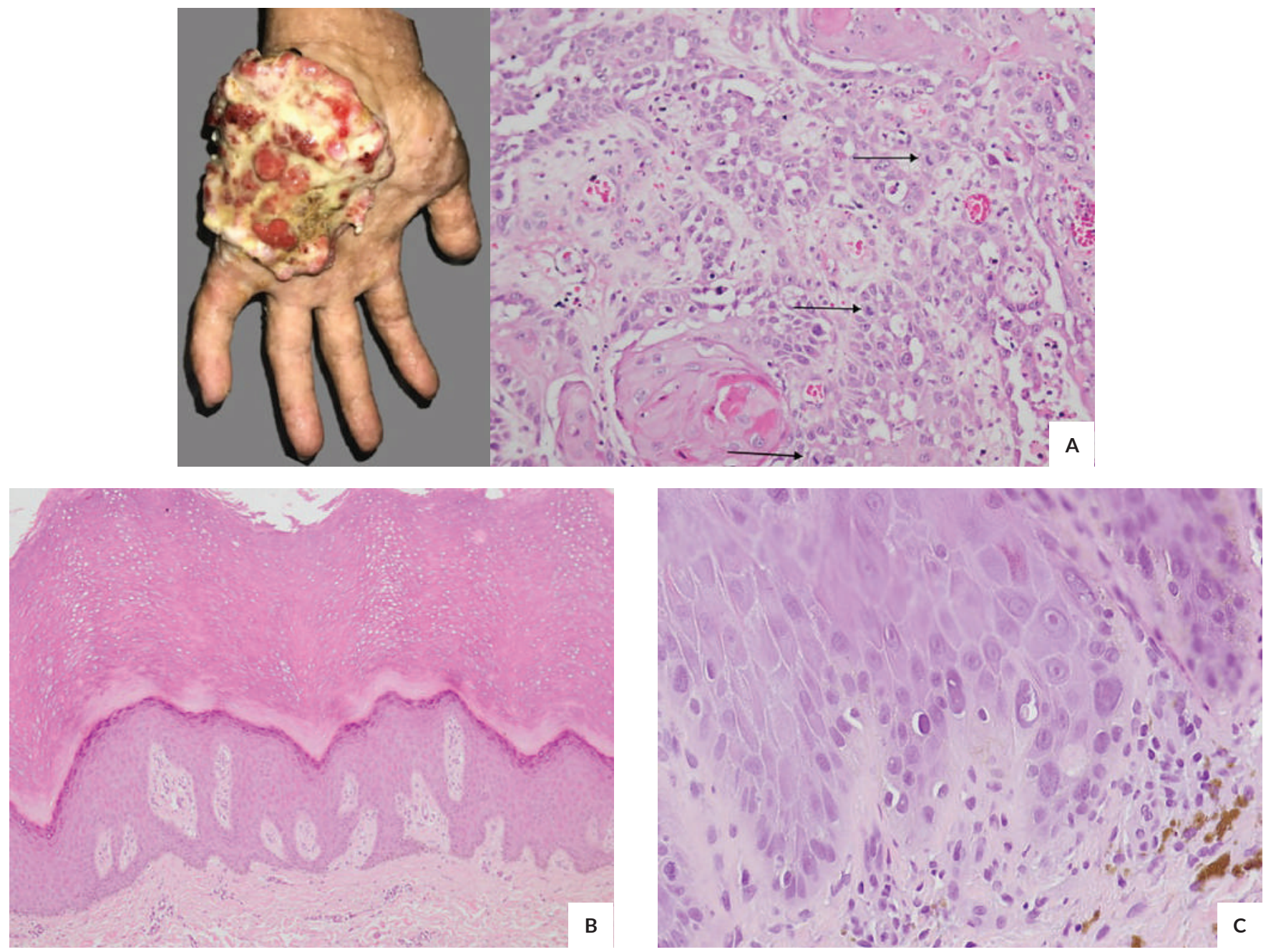

Figure 2. Histopathologic Findings. A. On the left ventral hand, there was a solitary, irregularly-shaped well-defined $\sim 9 \mathrm{~cm}$, fungating foul-smelling tumor with an erythematous border and granular purulent base. Hematoxylin-eosin (H\&E) stain of wedge biopsy showed atypical cells (black arrows) with horn pearls, consistent with well-differentiated squamous cell carcinoma (20x). B. Hematoxylin-eosin (H\&E) stain of skin biopsy taken from a hyperkeratotic papule on the dorsal foot, showing compact hyperkeratosis, mild papillomatosis, hypergranulosis, psoriasiform hyperplasia, perivascular infiltrates of lymphocytes, and histiocytes, with minimal atypia (10x). C. Biopsy taken from a hyperkeratotic papule on the left thigh, showing acantholytic epidermis and atypical keratinocytes, consistent with squamous carcinoma in-situ (40x).

also had elevated urine arsenic levels $(34.3 \mathrm{ug} / \mathrm{L}$, normal value: $<10 \mathrm{ug} / \mathrm{L}$ ), and biopsy of a hyperkeratotic papule from the right dorsal foot was consistent with arsenical keratosis.

On further work-up, no internal cancer was reported. The patient underwent below the elbow amputation of the left arm for the squamous cell carcinoma. He was referred to Rehabilitation Medicine for post-operative care. Nephrology and Hematology were also co-managing services for findings of mild anemia and renal parenchymal disease. For the hyperkeratotic lesions, he was started on urea 20\% + salicylic acid 10\% ointment twice a day. Acitretin $1 \mathrm{mg} / \mathrm{kg} /$ day was initiated as therapy and chemoprevention. Due to mucocutaneous side effects of intolerable, severe dry lips and cheilitis after one week of treatment, the dose was decreased to $0.5 \mathrm{mg} / \mathrm{kg} / \mathrm{day}$ for the next eight weeks, and later maintained on $0.3 \mathrm{mg} / \mathrm{kg} /$ day. Partial regression seen as flattening of hyperkeratotic lesions was achieved at the end of eleven weeks (Figure 3). Treatment has been well tolerated by the patient under laboratory monitoring of liver function test, creatinine, and lipid profile. The case was subsequently endorsed to the Department of Health $(\mathrm{DOH})$ and local government unit (LGU) of Los Baños, Laguna for community assessment and source control.

\section{DISCUSSION}

In 2005, the WHO published a manual on field case detection on arsenicosis. ${ }^{2}$ They presented a case definition algorithm based on the presence of melanosis and/or keratosis (Figure 4). Based on this manual and the presence 

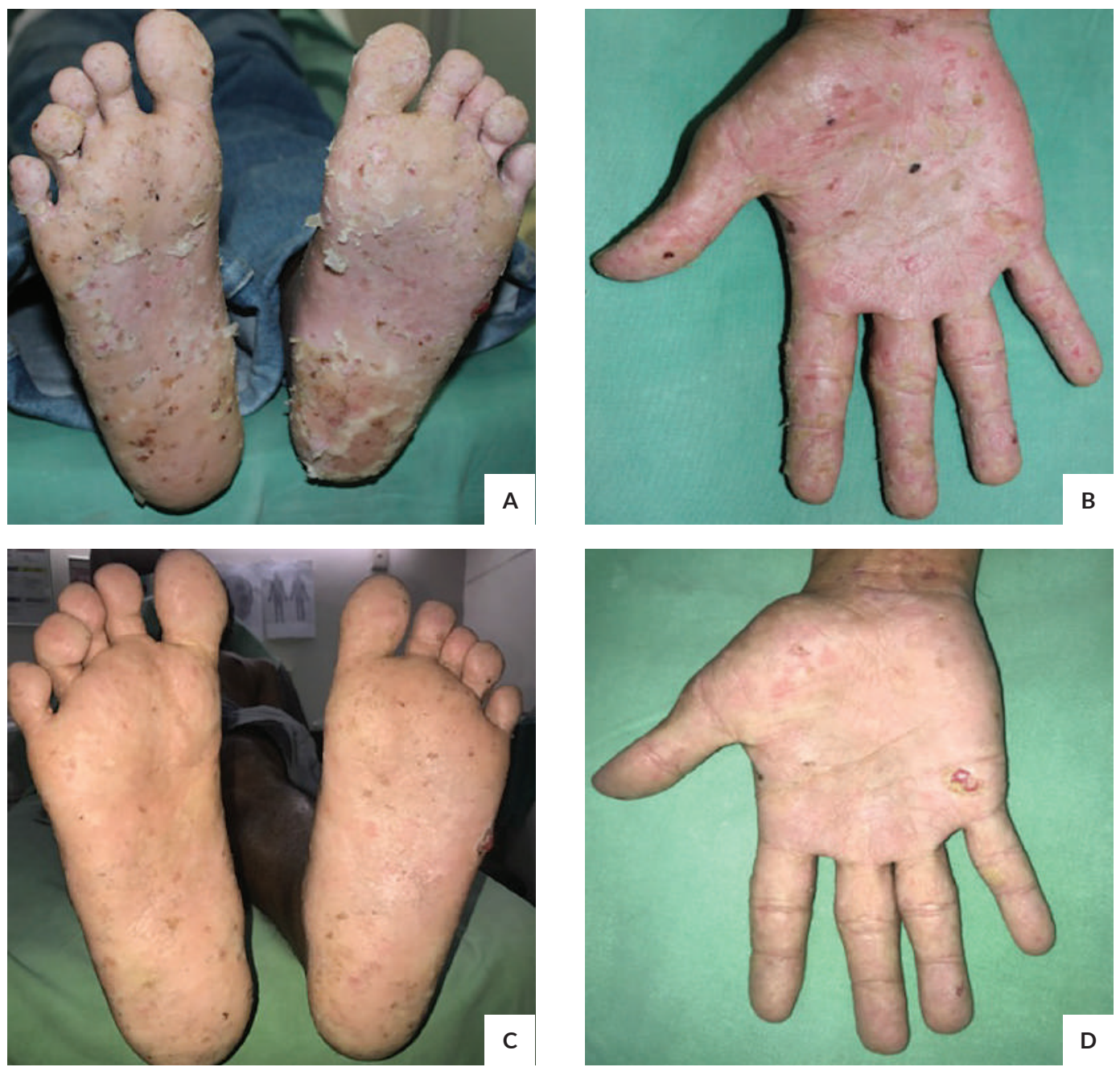

Figure 3. Response to Treatment. Response to treatment with topical keratolytics and oral acitretin after nine weeks (A and B), and after eleven weeks (C and D).

of hyperkeratotic papules on a background of speckled pigmentation resembling the classic description of 'raindrops on a dusty road,' a diagnosis of arsenicosis was made on this case, supported by ancillary tests, and histopathology of selected lesions.

In the Philippines, a number of cases of arsenic poisoning have been documented. In 2005, arsenic level was noted to exceed normal levels from soil samples near Mount Apo, where over thirty barangay communities were situated. ${ }^{3}$ Recently in 2014, 70\% of residents living in a community near Mount Pinatubo were found to have arsenicosis. ${ }^{4}$ In this case, the patient resides in a barangay near Mount Makiling, in Los Baños, Laguna.

Once arsenic is ingested, it is rapidly cleared from the blood, metabolized in the liver via methylation to form monomethylarsonic acid (MMA) and dimethylarsinic acid (DMA), with $75 \%$ excreted in the urine. ${ }^{5}$ The methylation is made possible through the activity of the S-arsenic methyltransferase (SAM) enzyme. The SAM is the center of epigenetic studies linking arsenic metabolism and an individual's genetic makeup in arsenic toxicity. Studies have shown genetic polymorphisms at 10q24.32 locus harboring AS3MT gene which encodes the arsenic methyltransferase enzyme. ${ }^{6}$ Arsenic-induced oxidative stress causes depletion of antioxidants and methyl group donors, including SAM, resulting to reduced arsenic excretion. The imbalance in arsenic metabolism results to greater deposition in the skin, hair, and nails due to arsenic's affinity to sulfhydryl groups found in these ectodermal tissues, leading to the clinical manifestations of arsenicosis. The resultant direct DNA damage and inhibition of DNA repair are related to epigenetic reprogramming contributing to arsenic-induced carcinogenesis. ${ }^{7}$ Skin cancer is the most common form of malignancy, arising from arsenical keratoses over time from a hyperkeratotic papule or arising de novo. ${ }^{8}$

The management of arsenicosis remains less than ideal as randomized controlled trials on these cases are lacking. ${ }^{2}$ The most practical intervention is limiting exposure by 


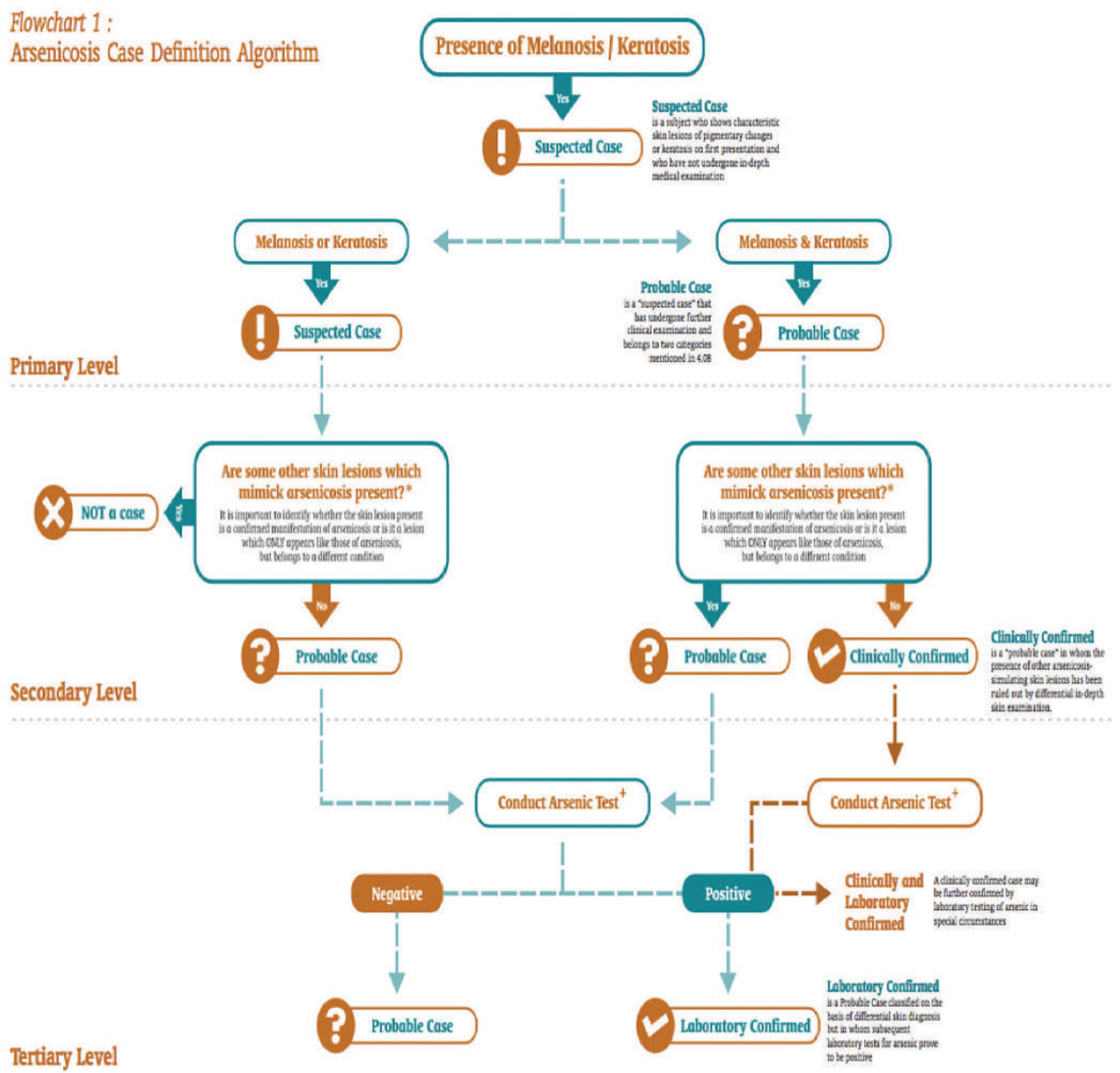

Figure 4. World Health Organization (WHO) arsenic case definition algorithm. Lifted from Caussy D, World Health Organization. A Field Guide for Detection, Management and Surveillance of Arsenicosis Cases.; 2005.

not drinking arsenic-contaminated water. Symptomatic treatment of hyperkeratotic papules using keratolytics such as salicylic acid and urea has been recommended and utilized. ${ }^{2,4}$ Medical surveillance for latent complications such as internal malignancies, with particular attention to the lungs, liver, and kidney, and provision of psychosocial support are also vital in the management. Chelation is generally reserved for acute arsenic poisoning and symptomatic patients with arsenicosis, presenting with elevated urinary arsenic level, indicating recent exposure; hence, this therapy was not done in the patient.
A number of case reports on the use of acitretin in arsenicosis have been documented showing promising results. ${ }^{9-12}$ Retinoids exert their effect via regulation of proteins and signal transduction genes involved in cellular proliferation and apoptosis. ${ }^{13}$ For how long a patient must be given acitretin for chemoprevention remains to be investigated. As studies have shown its beneficial effects in chemoprevention of internal malignancies, despite lack of guidelines, it appears prudent to give the medication indefinitely among high-risk patients, with regular monitoring for systemic side effects. ${ }^{14}$ 
More than just complying with the present WHO cut-off of arsenic level in drinking water, the challenge lies in identifying who among the population are susceptible. Perhaps, in tracing geochemical sources, it is possible, as this case has illustrated, that residence and/or occupation near volcanoes can be a risk factor for arsenicosis. The natural dissolution of minerals and the consequent leaching into groundwater can lead to arsenic contamination. Out of the more than 600 volcanoes reported by PHIVOLCS as of $2008,,^{15}$ it is imperative to determine how many of these volcanoes have nearby communities that use groundwater source for drinking, and how many of their population should be monitored for possible arsenicosis and thereby prevent the development of skin carcinomas and other malignancies. In light of the genome-associated risk related to susceptibility to arsenic toxicity, conducting genetic studies for the patient appears to be the next big step, but would be cost-intensive in the setting of large-scale public health screening. It could, however, be considered diagnostically beneficial in defining susceptibility subgroups in the future.

\section{CONCLUSION}

Detailed history taking and familiarization with dermatologic clues related to suspected arsenic poisoning cannot be over-emphasized. If the patient simply underwent surgical management without referral to other services, there would have been no realization that this is a public health problem more than just an individual health concern. There is a need for multi-disciplinary management in designing a sustainable plan for source control, case detection, treatment, and further prevention of long-term complications, including malignancies.

\section{Acknowledgement}

The authors would like to acknowledge the help and support of the department of Toxicology, Philippine General Hospital; special thanks to Dr. Carissa Paz C. Dioquino, head of the National Poison and Management Control Center (NPMCC); Dr. Allan P. Dionisio, training officer of the Department of Family and Community Medicine; Dr. Leslie T. Garcia, Dr. Nowell Benedict C. Catbagan, and Dr. Beethoven N. Bongon for their contribution to this report.

\section{Statement of Authorship}

All authors approved the final version submitted.

\section{Author Disclosure}

All authors declared no conflicts of interest.

\section{Funding Source}

This paper was funded by the authors. No external funding agency.

\section{REFERENCES}

1. World Health Organization. Exposure to arsenic: A major public health concern. In: Geneva: Public Health and Environment.; 2010:1-5.

2. Caussy D, World Health Organization. A Field Guide for Detection, Management and Surveillance of Arsenicosis Cases.; 2005.

3. Murcott S. Philippines. In: Arsenic Contamination in the World. IWA Publishing; 2012:157-9.

4. Sy SMT, Salud-Gnilo CM, Yap-Silva C, Tababa EJL. A retrospective review of the dermatologic manifestations of chronic arsenic poisoning in the Philippines. Int J Dermatol. 2017;56(7):721-5.

5. Munday S. Arsenic. In: Hoffman RS, Howland MA, Lewin NA, Nelson LS, Goldfrank LR, eds. Goldfrank's Toxicologic Emergencies. 10th ed. New York: Mcgraw-Hill Education; 2015:1169.

6. Karagas MR, Gossai A, Pierce B, Ahsan H. Drinking water arsenic contamination, skin lesions, and malignancies: a systematic review of the global evidence. Curr Env Heal Rep. 2016;2(1):52-68.

7. Bailey KA, Smith AH, Tokar EJ, et al. Mechanisms underlying latent disease risk associated with early-life arsenic exposure: current research trends and scientific gaps. Environ Health Perspect. 2016;124(2):170-5.

8. Martinez VD, Becker-Santos DD, Vucic EA, Lam S, Lam WL. Induction of human squamous cell-type carcinomas by arsenic. J Skin Cancer. 2011;2011:1-9.

9. Pratt M, Wadden P, Gulliver W. Arsenic Keratosis in a Patient from Newfoundland and Labrador, Canada: Case Report and Review. J Cutan Med Surg. 2016;20(1):67-71.

10. Wollina U.Arsenic and skin cancer - case report with chemoprevention. Our Dermatology Online. 2016;7(2):172-5.

11. Yerebakan O, Ermis O, Yilmaz E, Basaran E. Treatment of arsenical keratosis and Bowen's disease with acitretin. Int J Dermatol. 2002;41(2):84-7.

12. Khandpur S, Sharma VK. Successful Treatment of Multiple Premalignant and Malignant Lesions in Arsenical Keratosis with a Combination of Acitretin and Intralesional 5-Fluorouracil. J Dermatol. 2003;30(10):730-4.

13. Amann PM, Eichmüller SB, Schmidt J, Bazhin A V. Regulation of gene expression by retinoids. Curr Med Chem. 2011;18(9):1405-12.

14. Bettoli V, Zauli S, Virgili A. Retinoids in the chemoprevention of non-melanoma skin cancers: why, when and how. J Dermatolog Treat. 2013;24(3):235-7.

15. Philippine Institute of Volcanology and Seismology. Volcano Monitoring [Online]. 2008 [cited 2008 May]. Available from http://www.phivolcs.dost.gov.ph/. 